\title{
The Azotobacter vinelandii gene algJ encodes an outer-membrane protein presumably involved in export of alginate
}

\author{
Bernd H. A. Rehm $\dagger$ \\ Tel: +1 604822 3489. Fax: +1 604822 6041. e-mail: bernd@hancock.microbiology.ubc.ca
}

Lehrstuhl für Biologie der Mikroorganismen, RuhrUniversităt Bochum, 44780 Bochum, Germany

\begin{abstract}
The algJ gene from Azotobacter vinelandii was cloned using a labelled RNA probe representing the coding region of the algE gene from Pseudomonas aeruginosa. DNA sequencing revealed an ORF of 1452 bp encoding a protein of 484 amino acid residues with a calculated molecular mass of 54611 Da. An RNA probe corresponding to algE was also used for Southern hybridization of chromosomal DNA, which showed that algE-related DNA sequences are also present in the alginate-producing phytopathogen species Pseudomonas marginalis and Pseudomonas syringae pv. glycinea. The coding region of algJ was subcloned in the expression vector pT7-7, leading to a corresponding gene product with an apparent molecular mass of $54 \mathrm{kDa}$ which could be identified in the outer membrane (OM) of Escherichia coli BL21(DE3). Additionally, a cross-reacting protein with the same molecular mass was also found in the OM of $A$. vinelandii using an anti-AlgE antiserum. The derived amino acid sequence of AlgJ shared approximately $52 \%$ identity with AlgE from $P$. aeruginosa. The hydrophilicity profile as well as the amphipathicity of regions in the amino acid sequence of AlgJ showed significant similarities to AlgE. Based on these data, a topological model of AlgJ was created with the aid of known structures of outer-membrane proteins. This model presents AlgJ as a $\beta$-barrel containing $18 \beta$-strands inserted in the OM.
\end{abstract}

Keywords: Azotobacter vinelandii, alginate, outer-membrane protein, export

\section{INTRODUCTION}

Alginate is an unbranched copolymer consisting of variable amounts of $\mathrm{D}$-mannuronic acid and $\mathrm{L}$-guluronic acid. This polymer is produced in copious amounts by marine brown algae and by bacteria of the genera Azotobacter and Pseudomonas (Gorin \& Spencer, 1966; Govan et al., 1981 ; Linker \& Jones, 1966). Alginate from brown algae is isolated on an industrial scale for several applications in biotechnology and biomedicine (Guiry \& Blunden, 1991; Skjåk-Bræk \& Martinsen, 1991; SoonShiong et al., 1993). The genetics and biochemistry of alginate biosynthesis have been extensively studied in

\footnotetext{
†Present address: Department of Microbiology and Immunology, University of British Columbia, Vancouver, Canada V6T 123.

Abbreviations: IM, inner membrane; OM, outer membrane; OMP, outermembrane protein.

The EMBL accession number for the nucleotide sequence reported in this paper is $X 86533$.
}

alginate-producing mutants of Pseudomonas aeruginosa, i.e. mucoid strains (May \& Chakrabarty, 1994). These mucoid strains play a crucial role as human pathogens in cystic fibrosis patients (Govan \& Harris, 1986), and alginate is one of the most important virulence factors (Gacesa \& Russell, 1990).

Generally, the early steps of alginate biosynthesis, which are localized in the cytosol and lead to the activated precursor GDPmannuronic acid, are well understood (May \& Chakrabarty, 1994). However, the final steps of alginate biosynthesis still remain unclear. Among these are the polymerization, transacetylation (only in bacteria), epimerization and finally the export of the alginate.

Azotobacter vinelandii, like several Pseudomonas species, synthesizes alginate as an exopolysaccharide, which contributes to the differentiation process of cyst formation (Sadoff, 1975; Terzaghi \& Terzaghi, 1986).

The first alginate gene cloned from $A$. vinelandii was the algE gene, encoding a $\mathrm{Ca}^{2+}$-dependent extracellular epi- 
merase (Ertesvåg et al., 1994). Recently, four other epimerase genes were identified in $A$. vinelandii, originating from a common ancestor gene by a complex rearrangement process (Ertesvåg et al., 1995). The epimerase genes are the only alginate genes so far characterized in $A$. vinelandii. Thus the genetics of alginate biosynthesis of $A$. vinelandii are poorly understood. In this study, the cloning of another alginate gene, algJ, encoding an outer-membrane protein (OMP) which might be involved in the export of alginate, based on its homology to AlgE from $P$. aeruginosa, is presented (Grabert et al., 1990 ; Rehm et al., 1994a, b). AlgE is an alginate-specific OMP with defined channel properties which is probably involved in the export of the exopolysaccharide alginate across the outer membrane (OM) (Rehm et al., 1994b). Genetic characterization of $A$. vinelandii alginate biosynthesis may enable a functional comparison with the $P$. aeruginosa alginate genes, and elucidation of the alginate biosynthesis of $A$. vinelandii could lead to the application of this organism in industrial production of defined alginates.

\section{METHODS}

Bacterial strains and plasmids. Escherichia coli JM109 $\left[e 14^{-}\right.$ ( $m$ cr $A) \operatorname{rec} A 1$ end $A 1$ gyr $A 96$ thi-1 bsdR $17\left(\mathrm{r}_{\mathbf{k}}^{-} \mathrm{m}_{\mathrm{k}}^{+}\right)$supE44 $\mathrm{rel} A 1$ $\Delta($ lac-pro $A B)\left(F^{\prime}\right.$ traD36 pro $A B$ lacl $\left.\left.{ }^{\mathrm{q}} \mathrm{Z} \Delta \mathrm{M} 15\right)\right]$ was used for cloning and for the preparation of plasmid DNA (Sambrook $e t$ al., 1989). Strain E. coli BL21(DE3) (containing the T7 RNA polymerase gene under control of the $l a c U^{\prime} / 5$ promoter inserted in the chromosome) was used for the expression studies (Studier \& Moffatt, 1986). A. vinelandii strain $\mathrm{E}$ was used for the construction of a $\lambda$-EMBL-3 genomic library and for the preparation of protein samples (Larsen \& Haug, 1971). The phytopathogen strains Pseudomonas marginalis HT041B and Pseudomonas syringae pv. glycinea GSPB1203 (Fett et al., 1986) were used for the preparation of chromosomal DNA, which was analysed by Southern hybridization.

Plasmid pBluescript KS (Stratagene) served for cloning and DNA sequencing. Plasmid pBHR1 was constructed by inserting the algJ-coding region into the NdeI and Bam HI sites of the expression vector pT7-7 (Studier \& Moffatt, 1986). The coding region of alg J was amplified by $\mathrm{PCR}$, inserting restriction enzyme sites $N d e \mathrm{I}$ and $\mathrm{Bam} \mathrm{HI}$ at the $\mathrm{N}$-terminal and C-terminal ends, respectively.

Media and genetic techniques. In general, bacteria were grown in Luria-Bertani (LB) broth. Medium containing $2 \%$ $(\mathrm{w} / \mathrm{v})$ tryptone, $1 \%(\mathrm{w} / \mathrm{v})$ yeast extract and additional salts was used to maximize protein production (Tabor \& Richardson, 1985). When required, media were supplemented with an antibiotic (ampicillin, $50 \mu \mathrm{g} \mathrm{ml}^{-1}$ ) in order to prevent plasmid segregation. Transformation of bacteria and all other genetic techniques were performed as described by Sambrook et al. (1989). DNA was sequenced according to the chain-termination method (Sanger et al., 1977) using an automatic laser fluorescence sequencer (ALF; Pharmacia). PCR was performed using Vent DNA polymerase (New England Biolabs) for a duration of 30 cycles $\left(40 \mathrm{~s}, 94{ }^{\circ} \mathrm{C} ; 40 \mathrm{~s}, 54^{\circ} \mathrm{C} ; 2 \mathrm{~min}, 72^{\circ} \mathrm{C}\right)$ with the thermal cycler PHC-3 (Techne). Oligonucleotides (N-terminus: $5^{\prime}$-dAAAAAACATATGAGTAGGAAGCAACGCATAAG CGCGGGACTGGGCC-3' ; C-terminus : 5' -dAAAAAAGGATCCTTAGAAGCGCCAGATCATGTCGACGAAGAC ACGGTGCA-3') were obtained from Appligene. Chromo- somal DNA was isolated according to Mak \& Ho (1991) and used as target DNA in the PCR.

Southern blot hybridization of genomic DNA. Chromosomal DNA was digested with the indicated restriction enzymes, electrophoresed and blotted to a Hybond membrane (Amersham). Subsequently the membrane was irradiated with UV light to bind the DNA (Sambrook et al., 1989). As a probe, digoxigenin-labelled RNA corresponding to the entire coding region of the algE gene from $P$. aeruginosa was used. The labelling reaction was performed with the previously described plasmid pTR7-2 using a T7 RNA polymerase digoxigeninlabelling kit (Boehringer Mannheim) (Rehm et al., 1994b). The labelling procedure was conducted according to the user's guide (Boehringer Mannheim). Briefly, the vector pTR7-2 expressing algE under control of the T7 promoter $\phi 10$ was linearized with HindIII. This allowed the production of run-off transcripts in vitro in the presence of digoxigenin 11-dUTP and the T7 RNA polymerase. Prehybridization and hybridization were done with a standard buffer containing $50 \%(\mathrm{v} / \mathrm{v})$ formamide under stringent conditions $\left(50^{\circ} \mathrm{C}\right)$ according to the user's guide (Boehringer Mannheim). The detection of hybridized labelled RNA was done using anti-digoxigenin Fab fragments, conjugated with alkaline phosphatase and the chemiluminescent substrate Lumigen PPD [4-methoxy-4-(3-phosphatephenyl) spiro-(1,2-dioxetane-3,2'-adamantane); Boehringer Mannheim]. The membranes were prewarmed for $15 \mathrm{~min}$ at $37^{\circ} \mathrm{C}$ and exposed to X-Omat AR film (Kodak) for 1-2 h.

Screening of the genomic library and analysis of the recombinant clones. A $\lambda$-EMBL- 3 genomic library of strain $A$. vinelandii $\mathrm{E}$ (Larsen \& Haug, 1971) was plated on LB medium with approximately $500-800$ plaques per plate. The library was screened with the digoxigenin-labelled RNA probe corresponding to the entire algE-coding region. The filters were hybridized and washed as described above. The initial positive plaques were picked and eluted in SM buffer $(0.1 \mathrm{M} \mathrm{NaCl}, 8 \mathrm{mM}$ $\mathrm{MgSO}_{4}, 0.05 \mathrm{M}$ Tris $/ \mathrm{HCl}, 0.01 \%$, w/v, gelatine, $\mathrm{pH} 7.5$ ). The plaques were purified by plating at low density and screening with the same RNA probe until all plaques were positive. $\lambda$ DNA of the positive clones was prepared as described by Sambrook et al. (1989). The $\lambda$ DNA was digested with different restriction enzymes and subjected to electrophoresis on a $0 \cdot 8 \%$ agarose gel to determine the presence of inserts by Southern hybridization.

Subcellular localization of recombinant AlgJ. Cells were disrupted by ultrasonication. The membrane fraction was prepared by centrifuging whole-cell lysate for $1 \mathrm{~h}$ at $40000 \mathrm{~g}$. OMs were prepared by solubilizing the inner membrane (IM) with $0.7 \%$ (w/v) N-lauroylsarcosine (Sigma) (Poxton et al., 1985). Contamination of the OM preparation with IM was calculated by determining the specific succinate dehydrogenase activity of the OM preparation relative to the envelope preparation (OM and IM).

Gel electrophoresis and Western immunoblotting. After SDS-PAGE (Lugtenberg et al., 1975), protein bands were visualized by staining with Coomassie brilliant blue R-250 $(0 \cdot 025 \%$, w/v; Bio-Rad).

Western blotting (Towbin et al., 1979) of OMPs was performed using PVDF membranes (Millipore). AlgJ was detected by cross-reaction with the polyclonal anti-AlgE antiserum (Rehm et al., 1994a) and an alkaline-phosphatase-antibody conjugate (Sigma) as a second antibody. Bound antibodies were detected by using the chromogenic substrate nitro blue tetrazolium and 5-bromo-4-chloro-3-indolyl phosphate (toluidine salt) (Boehringer Mannheim). 


\section{RESULTS}

\section{Immunological cross-reaction of OMPs from A. vinelandii using the monospecific anti-AlgE antiserum}

To determine the presence of an AlgE OMP homologue in the $\mathrm{OM}$ of $A$. vinelandii, we used an anti-AlgE antiserum for immunoblotting experiments. The OMPs of $A$. vinelandii were prepared by selective solubilization of the IM with $N$-lauroylsarcosine (Poxton et al., 1985). Immunoblotting experiments revealed three cross-reacting OMPs with apparent molecular masses of $35 \mathrm{kDa}, 54 \mathrm{kDa}$ and $70 \mathrm{kDa}$; however, the $54 \mathrm{kDa}$ protein showed the strongest signal (data not shown).

\section{Identification of DNA sequences homologous to algE among alginate-producing bacteria}

Chromosomal DNA of the alginate-producing bacteria $P$. syringae pv. glycinea, $P$. marginalis, $P$. aeruginosa and $A$. vinelandii was isolated and used for Southern hybridization. As a probe, digoxigenin-11-dUTP-labelled RNA, representing the entire coding region of algE from $P$. aeruginosa, was applied. This labelling was done using plasmid pTR7-2, which enabled overexpression of algE under the control of the T7 promoter $\phi 10$ (Rehm et al., 1994b; Tabor \& Richardson, 1985). All of the alginateproducing bacteria analysed in this study showed, under stringent conditions, specific hybridization signals (Fig. 1 ). These data indicate that genes similar to algE might be

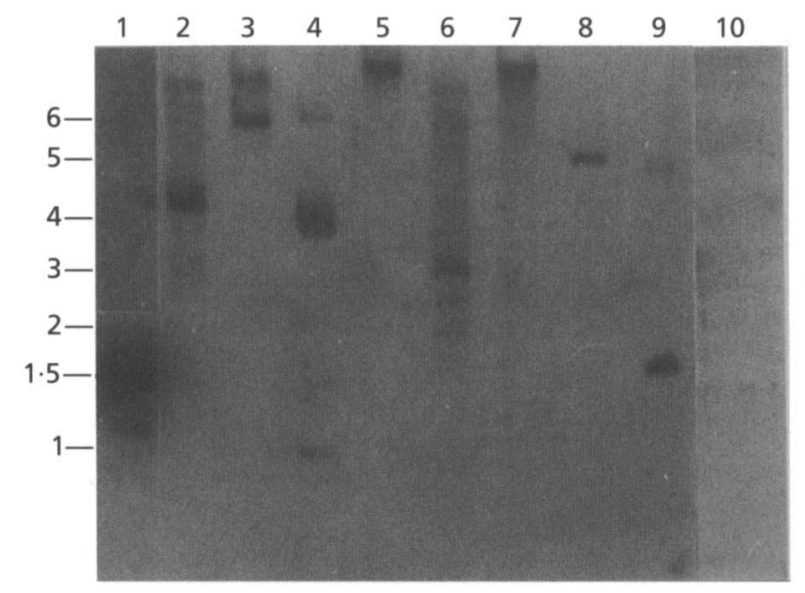

Fig. 1. Southern hybridization blot of digested chromosomal DNA from different alginate-producing bacteria probed with digoxigenin-labelled RNA corresponding to the algE gene from $P$. aeruginosa. Lanes: 1 , clone pKR22 digested with Xhol and HindllI, leading to a $1.5 \mathrm{~kb}$ DNA fragment representing the coding region of algE; 2,3 and 4 , chromosomal DNA from $P$. aeruginosa digested with EcoRI, HindIII and BamHI (positive control), respectively; 5, 6 and 7, chromosomal DNA from $A$. vinelandii digested with HindIII, EcoRI and BamHI, respectively; 8 and 9, chromosomal DNA digested with ECORI from $P$. marginalis and from $P$. syringae pv. glycinea, respectively; 10 , EcoRl-digested chromosomal DNA from $E$. coli JM109 as a negative control. Molecular sizes in $\mathrm{kb}$ are indicated on the left-hand side.
1 GGCCAACGCC TACGTCTTCG CACGTCTCGC CGTTTTGCAA GGCCGCCCCG ATTCCGAGCC 61 CCTGCTTCAG GAAATAGAGG CAATCTCGCT CCTGCAGAAC GTACCCGGGG TGAACAGATG 121 CTGCACGCGG AACAGCAGGC TCGTTACGGC GTGTGGCAGA CCTCGACGCA GCTGCAAGCC -35 181 ATGCAAAATC AATAGGAAGC ATTATGAGTA GGAAGCAACG CATAAGCGCG GGACTGGGCC 241 TGGGAGCCAG TCTGCTCTGC TGCAATCCGC TGTTCGCAGG

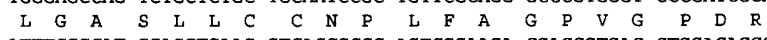
301 ATITCGGCAT GGAGGTGAAG GTCACCGCCC AGTCGGAAGA CGACCGTGAC CTGGACACCC $\begin{array}{lllllllllllllllllllllll}N & F & G & M & E & V & K & V & T & A & Q & S & E & D & D & R & D & L & D & T\end{array}$ 61 GCAGCGGCGG TGACGCCGAG GGTATCGCCC TCGACTTGCG GCCCTGGGTC TACGGCCAGC

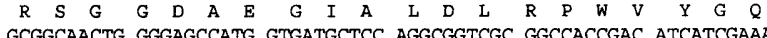
$\begin{array}{llllllllllllllllllll}R & G & N & W & G & A & M & V & M & L & Q & A & V & A & A & T & D & I & I & E\end{array}$ CCGACCCCAC CGATCCCAAC GAAGAACCGG GGGGCGATCC CGCGAACGGC TTCAGCCGCG

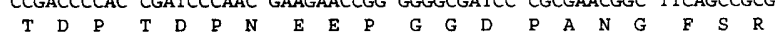
ACAGCAGCCG CGACCCGGAC AAGAGCTACC TCGCCCTGCG CGAATTCGAG CTCGGTACCA $\begin{array}{lllllllllllllllllllllllllll}D & S & S & R & D & P & D & K & S & Y & L & A & L & R & E & F & E & L & G & T\end{array}$ 01 TCGGCCGCCA GCGCATACGC AGCCTGACCA ACGAAGGCAC CTGGTGGGAC ATCCACATGG $\begin{array}{lllllllllllllllllllll}I & G & R & Q & R & I & R & S & L & T & N & E & G & T & W & W & D & I & H & M\end{array}$ AGTCGGTGAA CTGGACCATG GACACCAGCC TGCTGCGCGC CCAGGCCGGC GTCGCGAAAC

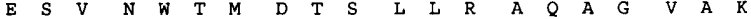
GCTTCGACGA ATACCGTACC GACCTGGACA ACCTGAGCGC GGAAGACAAG GACCGCACCC $\begin{array}{llllllllllllllllllllll}R & F & D & E & Y & R & T & D & L & D & N & L & S & A & E & D & K & D & R & T\end{array}$ ACGTCTTCG CGGCCTCGAC TACCAGTGGC GGCAAGGTCA CTGGGCCGGC TTCAAGGTGC

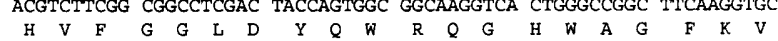
ACCACACCAG CGACGACGGC GACCTGCCGG ACAGCCAGAT GGATGTCTAC GAAGACCGCC

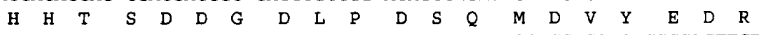
901 AGAGCAAGTC CTACACCGGC GACCTGACCT GGCTGAGCGT GCACCTGGAC CGCGACTTCT $\begin{array}{llllllllllllllllllll}Q & S & K & S & Y & T & G & D & L & T & W & L & S & V & H & L & D & R & D & F\end{array}$ TCAATCCTCG CTCGACCCG CCGATCAACI ACTGGGGCGA ATCACCTGG CTGACCGGCG

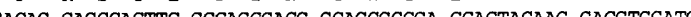
1021 AGATGGACAO GAGCCACITC GCCAGCGACG GCAGCGCCGA CCACTACAAG GACGTGGATG TCGACGCCTG GGCCGTGGAC CTCGGCCTGC GCTGGAACAT CAGCGACCGC TGGAACGTCG $\begin{array}{lllllllllllllllllllll}V & D & A & W & A & V & D & L & G & L & R & W & N & I & S & D & R & W & N & V\end{array}$ 141 GCGCGGCCTA TGCCCGCGGC CAGGCGGGCG AGGGCGACGA CGAGTCCGAA CAGTTCATGC $\begin{array}{cccccccccccccccccccc}\text { G A } & \text { A } & \text { Y } & \text { A } & \text { R } & \text { G } & Q & \text { A } & \text { G } & \text { E } & \text { G } & \text { D } & \text { D } & \text { E } & \text { S } & \text { E } & Q & \text { F } & M \\ \text { AGACCGGCCT } & \text { GCAGAGCAAC } & \text { CGCTCCACCT } & \text { TCACCGGCCT } & \text { GCAGACGCGC } & \text { ATCCACCGCT }\end{array}$ $\begin{array}{llllllllllllllllllll}Q & T & G & L & Q & S & N & R & S & T & F & T & G & L & Q & T & R & I & H & R\end{array}$ 1261 TCGGCGAAGC TTCCCGCGGC GAACTGACCA ACCTGCAGGT GGGCACCCTG TTCACCTCCT $\begin{array}{lllllllllllllllllllll}\text { F } & G & E & \text { A } & S & R & G & \text { E } & \text { L } & \text { T } & \text { N } & \text { L } & Q & \text { V } & \text { G } & \text { T } & \text { L } & \text { F } & \text { T } & \text { S }\end{array}$ 1321 GGAAGCCGAG AGAGGACCTC GAGACCAGCC TGATCTATCA CAAGTTCTGG CGCGTCGACG $\begin{array}{llllllllllllllllllll}W & K & P & R & E & D & L & E & T & S & L & I & Y & H & K & F & W & R & V & D\end{array}$ 1381 ATGACGAGGA TCTCGGCCAG AACGGCATCA GCCCGATCGA GAAGGACGGC AAGCCCGCGC

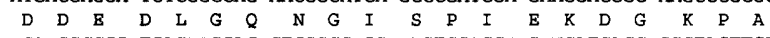
1441 TCAAGGCCGG TGAGAAGGAC CTCGGCCAGG AAGTCGACCT GATCATCACC CGCTACTTCA $\begin{array}{lllllllllllllllllllll}L & K & A & G & E & K & D & \text { L } & G & Q & E & \text { V } & \text { D } & \text { L } & \text { I } & \text { I } & \text { T } & R & \text { Y } & F\end{array}$ 1501 ACCAGGGCAT GTTGCCGGCC AACTGGGGTG GCGAGCTGGA CGAGCAGTCC GCACTGATCC

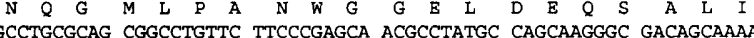
$\begin{array}{llllllllllllllllllllll}R & L & R & S & G & L & F & F & P & S & N & A & Y & A & S & K & G & D & S & K\end{array}$ TGCACCGTGT CTTCGTCGAC ATGATCTGGC GCTTCTAAGG TCCAGCGGCA CGCTGAGAGG $M \quad H \quad R \quad V \quad F \quad V \quad D \quad M \quad I \quad W \quad R \quad F$ 1681 ATCGAACATG AACGTGCAAA GAAAACTTGC ATCCACCCAG CTGAAACCCG TGTTGCTCGG

Fig. 2. DNA sequence of alg $J$ and the deduced amino acid sequence (single-letter code). The putative -10 and -35 regions, homologous to the $\sigma^{70}$ promoter, are underlined. The conserved ribosome-binding site is underlined and labelled with SD.

distributed among alginate-producing bacteria and that the algE gene appears to be conserved.

\section{Cloning of algJ from $A$. vinelandii and DNA sequence analysis of algJ}

The RNA probe described above was used for screening of a $\lambda$ gene library representing the $A$. vinelandii genome. A hybridizing $\lambda$ clone (pBHR100) with an approximately $20 \mathrm{~kb}$ insert was isolated. Further hybridization experiments confirmed that the DNA sequence homologous to algE was located on EcoRI fragments of $2 \cdot 3 \mathrm{~kb}, 3 \cdot 1 \mathrm{~kb}$ and $0.4 \mathrm{~kb}$. DNA sequencing of the complete $2 \cdot 3 \mathrm{~kb}$ and $0.4 \mathrm{~kb}$ EcoRI DNA fragments and part of the $3.1 \mathrm{~kb}$ EcoRI DNA fragment as well as of subclones comprising the EcoRI sites connecting the DNA fragments led to the identification of an ORF of $1452 \mathrm{bp}$, representing the algJ gene (Fig. 2). DNA sequence comparison with the 


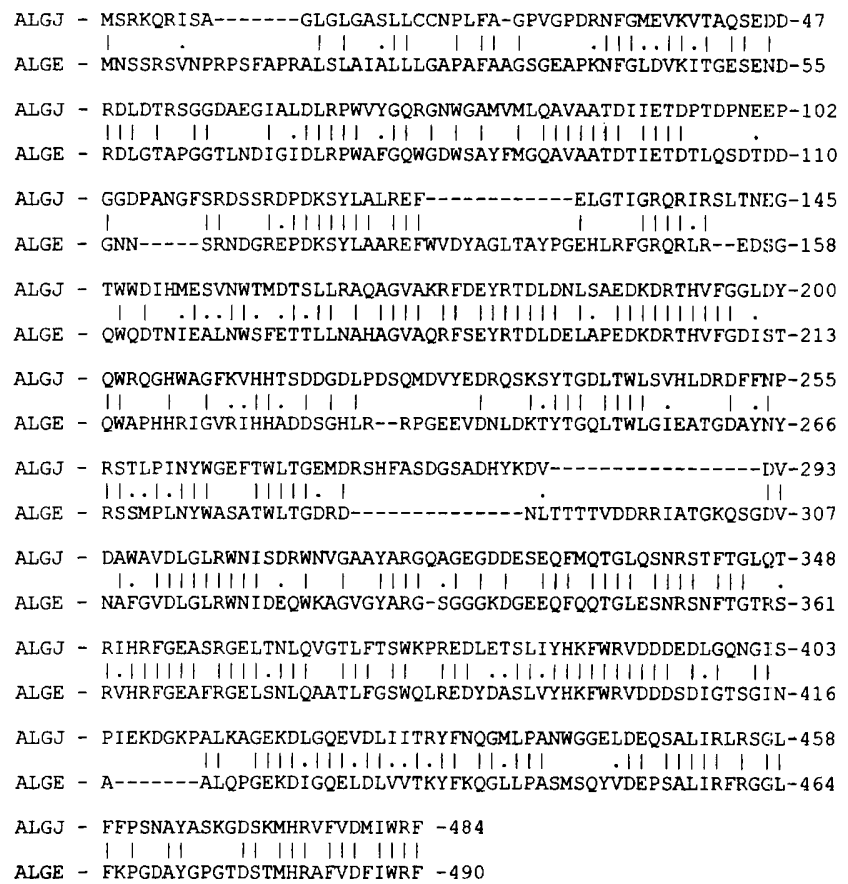

Fig. 3. Alignment of the deduced amino acid sequences of AlgJ and AlgE. The structure-genetic matrix with an open gap cost of 7 and a unit gap cost of 1 was used. |, Two identical aligned residues; $\cdot$, two similar aligned residues. Amino acids said to be similar are: $A, S, T ; D, E ; N, Q ; R, K ; I, L, M, V ; F, Y, W$.

GenBank (release 91)/EMBL (release 43.0) databases showed significant similarity ( $\sim 47 \%$ identity) only with algE from $P$. aeruginosa (data not shown) (Chu et al., 1991). DNA sequence analysis indicated a potential ribosomebinding site, AGGAA, five nucleotides upstream of the start codon ATG at position 204 (Fig. 2). This spacing between the potential ribosome-binding site and the start codon agrees with the preferred spacing of the ribosomebinding site in E. coli (Shine \& Dalgarno, 1975).

A weak homology in the -10 and -35 regions with the $\sigma^{70}$ promoter from E. coli was found (Fig. 2). The G/C content of the analysed DNA was $64 \cdot 2 \%$. Furthermore, 30 nucleotides downstream of algJ, the alg $G$ gene, encoding an epimerase, was identified (B. H. A. Rehm, H. Ertesvåg \& S. Valla, unpublished results).

The alg $G$ gene possessed no potential promoter region but had a conserved ribosome-binding site, suggesting an operonic organization. This alg $G$ gene from $A$. vinelandii was overexpressed in $E$. coli, partially purified and the gene product showed epimerase activity (B. H. A. Rehm, H. Ertesvåg \& S. Valla, unpublished results).

The upstream region of alg J was found to be similar ( $73 \%$ identity; 165/226) to the upstream region of algE from $P$. aeruginosa (GenBank release 91/EMBL release 43.0). This homology strongly suggests that this DNA region might encode the same protein, possibly involved in alginate biosynthesis, in $A$. vinelandii and $P$. aeruginosa.

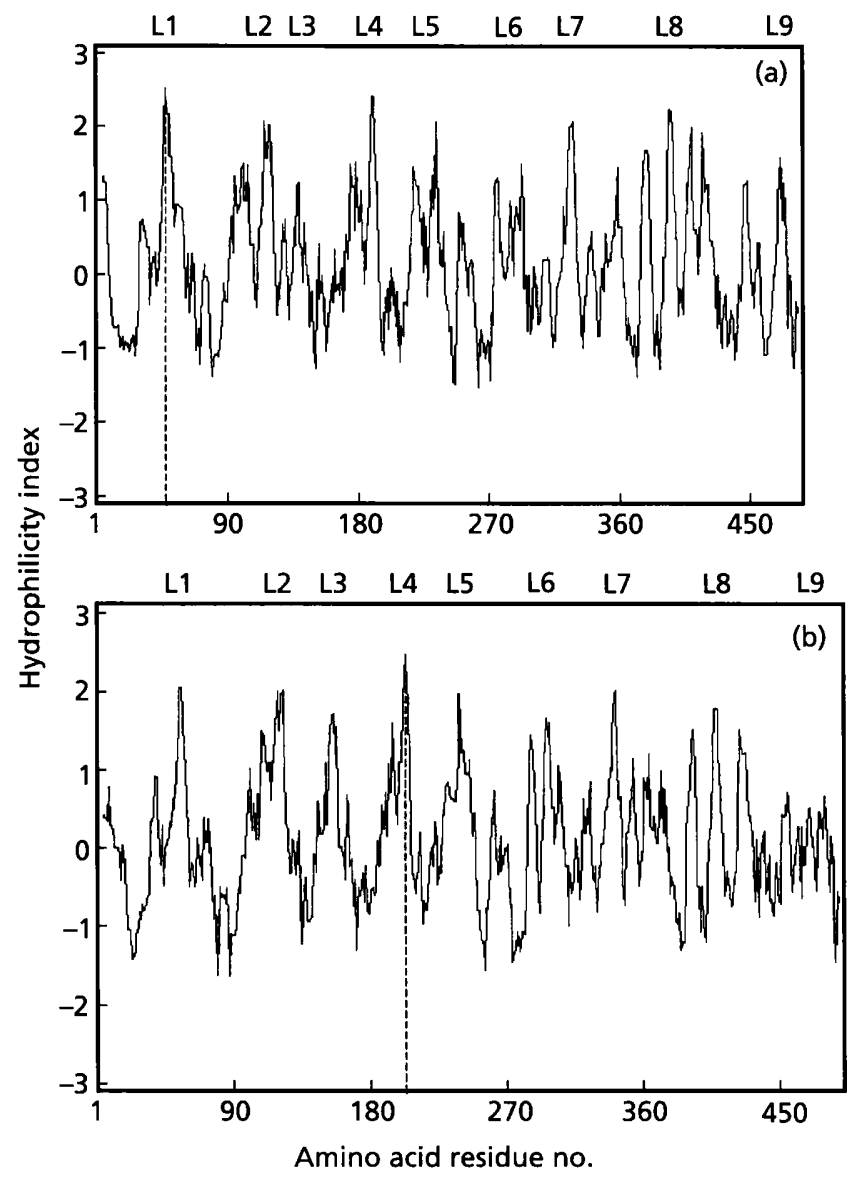

Fig. 4. Comparison of the hydrophilicity profiles of (a) AlgJ and (b) AlgE according to Hopp \& Woods (1981). Loops (L1-L9) were predicted, based on the hydrophilicity profile, as corresponding to hydrophilic maxima.

\section{Analysis of the algJ deduced amino acid sequence}

The amino acid sequence deduced from algJ revealed a $\sim 52 \%$ identity with $\mathrm{Alg} \mathrm{E}$ and no significant similarity to any other protein in the GenBank (release 91) and EMBL (release 43.0) databases (Fig. 3). The amino acid sequence was analysed using the program PC/Gene (IntelliGenetics release 6.7). A conserved signal sequence with a potential cleavage site between positions 25 and 26 was found. This cleavage site corresponds to the $(-3,-1)$ rule (von Heijne, 1984). Acidic pI values of 4.47 (precursor form) and 4.37 (mature form) could be calculated. Hydrophilicity profiles were calculated for $\mathrm{AlgE}$ and $\mathrm{Alg} J$ and the comparison revealed a strong similarity (Fig. 4) (Hopp \& Woods, 1981).

\section{Topological model of AlgJ}

A topological model of Alg J was created (Fig. 5) based on the following criteria: (i) the prediction of extracellular loops using the hydrophilicity profile according to Hopp \& Woods (1981), where hydrophilic maxima correspond to cell-surface-exposed loops; (ii) amphipathic regions, 


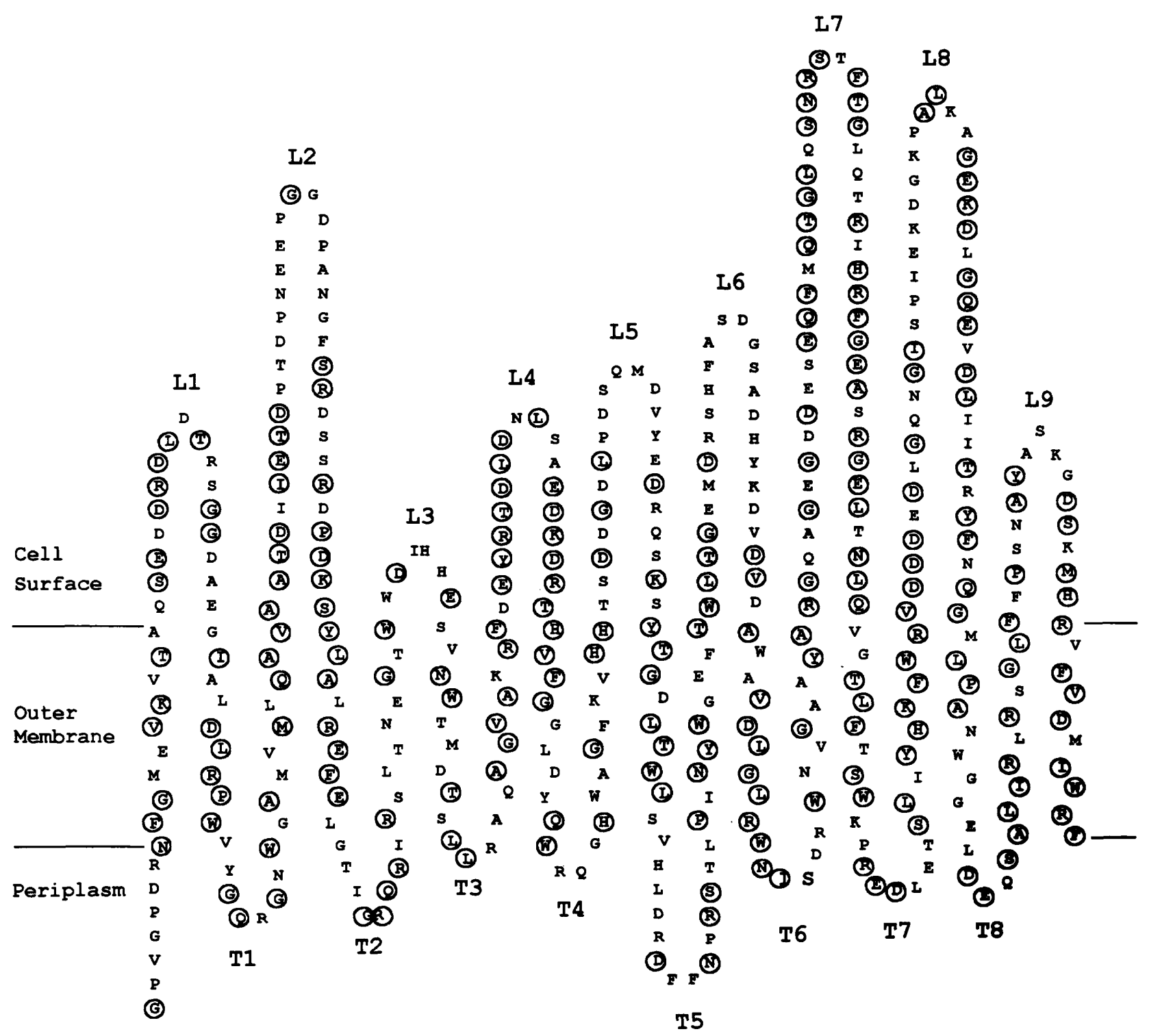

Fig. 5. Topological model of mature AlgJ based on its amino acid sequence (single-letter code). The $\beta$-barrel structure shown consists of 18 anti-parallel $\beta$-strands, 9 loops (L1-L9) and 8 turns (T1-T8). Identical amino acid residues, based on comparison of the amino acid sequences of AlgE and AlgJ, are circled.

which separate the loops and probably form $\beta$-strands; (iii) turn predictions according to Paul \& Rosenbusch (1985), which should not be located in the $\beta$-strands, but should separate the $\beta$-strands representing the periplasmic exposed $\beta$-turns; (iv) $\alpha$-helix prediction only in the loop regions; and finally (v) with the aid of known OMP structures based on high-resolution X-ray analysis (Cowan et al., 1992; Schirmer et al., 1995).

Using these criteria, which were also used for the accurate prediction of PhoE (Tommassen, 1988), AlgJ is presented as a $\beta$-barrel, consisting of 18 antiparallel amphipathic $\beta$ strands spanning the OM, eight $\beta$-turns (T1-T8) at the periplasmic site and nine loops (L1-L9) exposed to the cell surface (Fig. 5). In $\beta$-strands 4 and 7 , positively charged residues (arginine and lysine, respectively) are exposed to the hydrophobic core. Single hydrophilic residues in the $\beta$-strands exposed to the external hydrophobic core of the putative AlgJ structure could possibly be tolerated as was recently shown for the crystal structure of LamB (Schirmer et al., 1995). Basically, the topological model of AlgJ (Fig. 5) is very similar to those already postulated and verified for some other integral OM proteins, e.g. the specific porins LamB and PhoE from E. coli (Schirmer et al., 1995; Tommassen, 1988).

\section{Overexpression of algJ in E. coli and localization of the gene product to the $O M$}

For the overexpression of algJ in E. coli, PCR was used to amplify the coding region of algJ and to introduce the restriction sites NdeI and Bam $\mathrm{HI}$ at the ends of the PCR product. These restriction sites were used to clone the 


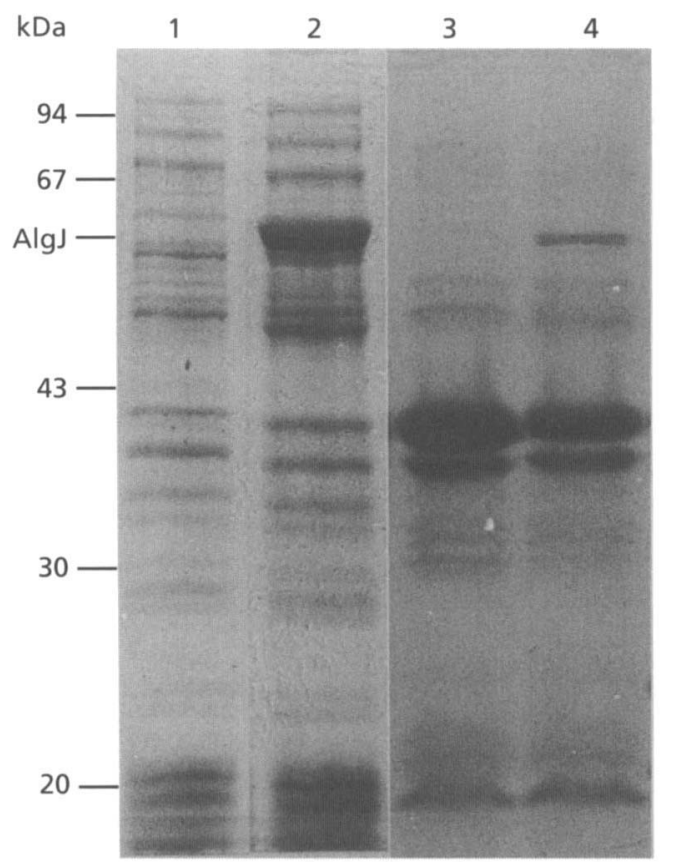

Fig. 6. SDS-PAGE demonstrating expression of algJ in $E$. coli BL21(DE3) and its localization in the OM. Lanes: 1 and 2, whole-cell lysate of $E$. coli BL21(DE3) (induced with $1 \mathrm{mM}$ IPTG) containing vector pT7-7 and containing plasmid pBHR1, respectively; 3 and 4, OMP preparations of $E$. coli $B L 21(D E 3)$ (induced with $1 \mathrm{mM}$ IPTG) containing vector pT7-7 and containing plasmid pBHR1, respectively. Molecular masses in $\mathrm{kDa}$ and the position of recombinant AlgJ are indicated on the left-hand side.

coding region into vector $\mathrm{p} T 7-7$, thereby producing the construct pBHR1 (Tabor \& Richardson, 1985). The vector provides a conserved ribosome-binding site and enabled overexpression of algJ under the control of T7 promoter $\phi 10$ in E. coli BL21(DE3) (Fig. 6) (Studier \& Moffatt, 1986; Tabor \& Richardson, 1985). This E. coli strain contains the T7 RNA polymerase gene integrated in the chromosome under control of the IPTG-inducible lac UV 5 promoter (Studier \& Moffatt, 1986). Subcellular localization revealed that recombinant $\mathrm{Alg} \mathrm{J}$ was secreted and incorporated in the $\mathrm{OM}$ of the overexpressing E. coli strain (Fig. 6).

\section{DISCUSSION}

The Southern hybridization data indicated that genes similar to algE are distributed and conserved among alginate-producing bacteria. Thus, OMPs homologous to $\mathrm{AlgE}$ ( $P$. aeruginosa) might also play an important role in the alginate biosynthesis of these bacteria as shown for $P$. aeruginosa. The algE-defective mutant of $P$. aeruginosa is not capable of producing alginate unless it is complemented with the algE gene (Chu et al., 1991). Accordingly, DNA sequences that were homologous to the $P$. aeruginosa alginate genes $\operatorname{alg} A, \operatorname{alg} D$ and $\operatorname{algR}$ could be found in 23 species of the genus Pseudomonas in rRNA homology group I, with the exception of Pseudomonas stutzeri. Homologous DNA sequences of at least one of those alginate genes were found in the species Xanthomonas campestris, Azomonas macrocytogenes and $A$. vinelandii in the same homology group (Fialho et al., 1990). To support the idea that $A$. vinelandii produces a protein similar to $\mathrm{A} \lg \mathrm{E}$ in the $\mathrm{OM}$, we used a polyclonal anti- $\mathrm{Alg} \mathrm{E}$ antiserum. Immunoblotting of OMPs of $A$. vinelandii revealed the expected cross-reactivity. An OMP with an apparent molecular mass of $54 \mathrm{kDa}$ could be detected, and was considered as a candidate for the AlgE-related OMP. Cloning and DNA sequencing of algJ from $A$. vinelandii confirmed the presence of a related gene. The predicted amino acid sequence of $\mathrm{Alg} \mathrm{J}$ indicated the presence of a signal peptide of 25 amino acids, with a putative cleavage site for leader peptidase 1 conforming with the $(-3,-1)$ rule and an amphipathic $\mathrm{C}$-terminal region ending with a phenylalanine residue. These features suggested that $\mathrm{Alg} J$ was secreted through the cytoplasmic membrane and localized in the OM (Struyve et al., 1991; von Heijne, 1984). This was confirmed by the localization of recombinant $\mathrm{AlgJ}$ in the OM of E. coli and by the identification of a cross-reacting protein in the membrane fraction of $A$. vinelandii. The same result was obtained in the case of the overexpression of algE from $P$. aeruginosa in E. coli, where a putative precursor could be identified in the cytoplasmic membrane (Rehm et al., 1994b). The presence of AlgJ as an OMP was additionally supported by the fact that it was possible to create a topological model of $\mathrm{Alg} J$ as an integral $\beta$-barrel in the OM using the criteria applied for the precise prediction of the structure of PhoE from $E$. coli (Tommassen, 1988). The model presented in this study is in good agreement with the model already presented for AlgE (Rehm et al., 1994b). Accordingly, $\mathrm{Alg} \mathrm{J}$ is predicted to consist of $18 \beta$-strands with 9 cellsurface-exposed loops and 8 periplasmic oriented $\beta$-turns. Recently, the crystal structure of the specific channel LamB was determined, which also revealed an 18-stranded antiparallel $\beta$-barrel (Schirmer et al., 1995).

Loops 4 and 7 of AlgJ showed extended stretches of amino acids that were identical to those in $\mathrm{AlgE}$, and they possessed a high density of charged amino acids, indicating a putative functional role of these loops in the binding and/or the translocation of the anionic alginate chain. Ionizable amino acid residues are involved in substrate binding and translocation in LamB from E. coli (Schirmer et al., 1995). Loops 4 and 7 might bend into the channel lumen, providing a binding site for the alginate oriented towards the periplasm. For AlgE, blocking of the channel with GDPmannuronic acid, the activated precursor of the alginate, has been shown, indicating a binding site for the alginate chain (Rehm et al., 1994b). In the case of LamB from E. coli it was shown that loops L2, L4 and L6 also contribute to the specificity of the channel (Schirmer et al., 1995). However, the functional role of $\mathrm{AlgJ}$ in alginate biosynthesis might be the export of the alginate across the $\mathrm{OM}$ as has been proposed for $\mathrm{Alg} E$ (Rehm et al., 1994b). Consequently, AlgJ is strongly suggested to be a specific channel protein with export function. There is only one other protein with a potential polysaccharide export function described so far, which is the OMP CtrA from Neisseria meningitidis. This OMP 
contains eight predicted $\beta$-strands and has been proposed to be involved in capsule formation (Frosch et al., 1992).

To confirm the topological model of $\mathrm{Alg} J$, it is necessary to perform mutagenesis, e.g. by insertion of certain epitopes or proteolytic sites into the loop regions, and to purify the protein in order to analyse its channel properties.

We are also currently performing DNA sequencing to analyse the complete $20 \mathrm{~kb}$ DNA fragment containing the suggested alginate gene cluster in $A$. vinelandii as well as Northern hybridizations to identify the potential polycistronic mRNA. Elucidation of the genetics and the biochemistry of alginate biosynthesis in $A$. vinelandii might enable the production of designed alginates and/or alginate production in recombinant $E$. coli containing a certain arrangement of alginate genes.

\section{ACKNOWLEDGEMENTS}

This research was supported by a grant of the Deutsche Forschungsgemeinschaft and the Minister für Wissenschaft und Forschung des Landes Nordrhein-Westfalen. The author also thanks Dr U. K. Winkler and Dr R. E. W. Hancock for scientific discussions and suggestions and Dr S. Valla for providing the lambda genomic library of $A$. vinelandii as well as his scientific contribution. The author gratefully acknowledges the technical assistance by Blanka Kutscher.

\section{REFERENCES}

Chu, L., May, T. B., Chakrabarty, A. M. \& Misra, T. K. (1991). Nucleotide sequence and expression of the algE gene involved in alginate biosynthesis by Pseudomonas aeruginosa. Gene 107, 1-10.

Cowan, S. W., Schirmer, T., Rummel, G., Steiert, M., Ghosh, R., Pauptit, R. A., Jansonius, J. N. \& Rosenbusch, J. P. (1992). Crystal structures explain functional properties of two E. coli porins. Nature 358, 727-733.

Ertesvåg, H., Doseth, B., Larsen, B., Skjåk-Bræk, G. \& Valla, S. (1994). Cloning and expression of an Azotobacter vinelandii mannuronan C-5-epimerase gene. J Bacteriol 176, 2846-2853.

Ertesvåg, H., Hoidal, H. K., Hals, I. K., Doseth, B. \& Valla, S. (1995). A family of modular type mannuronan $\mathrm{C}$-5-epimerase genes controls alginate structure in Azotobacter vinelandii. Mol Microbiol 16, 719-731.

Fett, W. F., Osman, S. F., Fishman, M. C. \& Siebles, T. S. (1986). Alginate production by plant pathogenic pseudomonads. Appl Environ Microbiol 52, 466-473.

Fialho, A. M., Zielinski, N. A., Fett, W. F., Chakrabarty, A. M. \& Berry, A. (1990). Distribution of alginate gene sequences in the Pseudomonas rRNA homology group I-Azomonas-Azotobacter lineage of superfamily B procaryotes. Appl Environ Microbiol 56, 436-443.

Frosch, M., Müller, D., Bousset, K. \& Müller, A. (1992). Conserved outer membrane protein of Neisseria meningitidis involved in capsule expression. Infect Immun 60, 798-809.

Gacesa, P. \& Russell, N. J. (1990). The structure and properties of alginate. In Pseudomonas Infection and Alginates, pp. 29-49. Edited by P. Gacesa \& N. J. Russell. London: Chapman and Hall.

Gorin, P. A. J. \& Spencer, J. F. T. (1966). Exocellular alginic acid from Azotobacter vinelandii. Can J Chem 44, 993-998.
Govan, J. R. W. \& Harris, G. S. (1986). Pseudomonas aeruginosa and cystic fibrosis: unusual bacterial adaptation and pathogenesis. Microbiol Sci 3, 302-308.

Govan, J. R. W., Fyfe, J. A. M. \& Jarman, J. R. (1981). Isolation of alginate-producing mutants of Pseudomonas fluorescens, Pseudomonas putida and Pseudomonas mendocina. J Gen Microbiol 125, 217-220.

Grabert, E., Wingender, J. \& Winkler, U. K. (1990). An outer membrane protein characteristic of mucoid strains of $P_{\text {seudomonas }}$ aeruginosa. FEMS Microbiol Lett 68, 83-88.

Guiry, M. D. \& Blunden, G. (editors) (1991). Seaweed Resources in Europe: Uses and Potential. New York: John Wiley.

von Heijne, G. (1984). How signal sequences maintain cleavage specificity. J Mol Biol 173, 243-251.

Hopp, T. P. \& Woods, K. R. (1981). Prediction of protein antigenic determinants from amino acid sequences. Proc Natl Acad Sci USA 78, $3824-3828$

Larsen, B. \& Haug, A. (1971). Biosynthesis of alginate. Part I. Composition and structure of alginate produced by $A$. vinelandii (Lipman). Carbobydr Res 17, 287-296.

Linker, A. \& Jones, R. S. (1966). A new polysaccharide resembling alginic acid isolated from pseudomonads. $J$ Biol Chem 241, 3845-3851.

Lugtenberg, B., Meijers, J., Peters, R., van der Hoek, P. \& van Alphen, L. (1975). Electrophoretic resolution of the 'major outer membrane protein' of Escherichia coli $\mathrm{K} 12$ into four bands. FEBS Lett 58, 254-258.

Mak, Y. M. \& Ho, K. K. (1991). An improved method for the isolation of chromosomal DNA from various bacteria and cyanobacteria. Nucleic Acids Res 20, 4101-4102.

May, T. B. \& Chakrabarty, A. M. (1994). Pseudomonas aeruginosa: genes and enzymes of alginate synthesis. Trends Microbiol 2, 151-156.

Paul, C. \& Rosenbusch, J. P. (1985). Folding patterns of porin and bacteriorhodopsin. EMBO J 4, 1593-1597.

Poxton, I. R., Bell, G. T. \& Barclay, G. R. (1985). The association in SDS-polyacrylamide gels of lipopolysaccharide and outer membrane proteins of Pseudomonas aeruginosa revealed by monoclonal antibodies and Western blotting. FEMS Microbiol Lett 27, 247-251.

Rehm, B. H. A., Grabert, G., Hein, J. \& Winkler, U. K. (1994a). Antibody response of rabbits and cystic fibrosis patients to an alginate-specific outer membrane protein of a mucoid strain of Pseudomonas aeruginosa. Microb Pathog 16, 43-51.

Rehm, B. H. A., Boheim, G., Tommassen, J. \& Winkler, U. K. (1994b). Overexpression of algE in Escherichia coli: subcellular localization, purification, and ion channel properties. J Bacteriol 176 , 5639-5647.

Sadoff, H. L. (1975). Encystment and germination of Azotobacter vinelandii. Bacteriol Rev 39, 516-539.

Sambrook, J., Fritsch, E. F. \& Maniatis, T. (1989). Molecular Cloning: a Laboratory Manual, 2nd edn. Cold Spring Harbor, NY: Cold Spring Harbor Laboratory.

Sanger, F., Nicklen, S. \& Coulson, A. R. (1977). DNA sequencing with chain-terminating inhibitors. Proc Natl Acad Sci USA 74, 5463-5467.

Schirmer, T., Keller, T. A. \& Rosenbusch, J. P. (1995). Structural basis for sugar translocation through maltoporin channels at $3 \cdot 1 \AA$ resolution. Science 267, 512-514.

Shine, J. \& Dalgarno, L. (1975). Determinant of cistron specificity in bacterial ribosomes. Nature 254, 34-38.

Skjăk-Bræk, G. \& Martinsen, A. (1991). Application of some algal polysaccharides in biotechnology. In Seaweed Resources in Europe: 
Uses and Potential, pp. 219-257. Edited by M. D. Guiry \& G. Blunden. New York: John Wiley.

Soon-Shiong, P., Feldman, E., Nelson, R., Heintz, R., Yao, Q., Yao, Z., Zheng, T., Merideth, N., Skjåk-Bræk, G., Espevik, T., Smidsrod, O. \& Sandford, P. (1993). Long-term reversal of diabetes by injection of immunoprotected islets. Proc Natl Acad Sci US.A 90, $5843-5847$.

Struyve, M., Moons, M. \& Tommassen, J. (1991). Carboxy-terminal phenylalanine is essential for the correct assembly of a bacterial outer membrane protein. J Mol Biol 218, 141-148.

Studier, F. W. \& Moffatt, B. A. (1986). Use of bacteriophage T7 RNA polymerase to direct selective high level expression of cloned genes. J Mol Biol 189, 113-130.

Tabor, S. \& Richardson, C. C. (1985). A bacteriophage T7 RNA polymerase/promoter system for controlled exclusive expression of specific genes. Proc Natl Acad Sci US A 82, 1074-1078.
Terzaghi, B. E. \& Terzaghi, E. (1986). Azotobacter biology, biochemistry and molecular biology. In Nitrogen Fixation, vol. 4, pp. 127-163. Edited by W. J. Broughton \& A. Puhler. Oxford: Clarendon Press.

Tommassen, J. (1988). Biogenesis and membrane topology of outer membrane proteins in Escherichia coli. In Membrane Biogenesis (NATO ASI series), pp. 351-373. Edited by J. A. Op den Kamp. Berlin: Springer Verlag.

Towbin, H., Staehelin, T. \& Gordon, J. (1979). Electrophoretic transfer of proteins from polyacrylamide gels to nitrocellulose sheets: procedure and some applications. Proc Natl Acad Sci US A 76, 4350-4354.

Received 30 August 1995; revised 8 December 1995; accepted 11 December 1995. 